7. Kruckmann.-Pigmentierung u. Wucherung der Netzhautneuroglia. Arch. f. Ophthal., Bd. LX, SS. 452-512, 1905.

8. Dimmer-Pillat. - Photographie der Fundus. Pl. 57, Fig. 1.

9. Wagenmann.-Experimentelle Untersuchungen über den Einfluss der Circulation in den Netzhaut; und Aderhaut-gefässen auf die Ernährung des Auges, insbesondere der Retina und über die Folgen der Sehnerven Durchschneidung. Arch.f. Ophthal., Vol. XXXVI, SS. 1-120, 1890.

10. Suganuma. - Ueber die pathologischen Veränderungen der chorioidealen Glashaut und des retinalen Pigmentepithels. Arch.f. Ophthal., Bd.CXV, SS. 87-128, 1924.

11. Zirm. - Ein Fall von bleibenden ausgedehnten Veränderungen der beiden Maculae durch direktes Sonnen-licht. Arch. f. Ophthal., Bd. LX, SS. 401-404, 1905.

12. Bedell.-Photographic history of a traumatic retino-choroiditis. Arch. of Ophthal., Vol. LVII, pp. 262-264, 1928.

13. Hugu nin, Marie. - Traumatic rupture of the ciliary arteries. La Clin. Ophtal., février, 1916. Abstracted by Thomson in Brit. Jl. of Ophthal. Vol. I, p. 99, 1917.

\title{
CONCOMITANT STRABISMUS AND HETEROPHORIA
}

BY

Kenneth R. Smith, M.D., B.S.(Lond.)

LATE ROYAL AIR FORCE MEDICAL SERVICE

\section{Children's Squint and Heterophoria}

THE meaning of the term heterophoria given by Mr. Hartridge is "a disturbance of the equilibrium of the muscles of the eyeball." The defect of sight which bears the same name in the flying community is an occasional failure of binocular vision. Sight with both eyes together is apt to break down, and then that of one eye only is used instead. Air pilots and those learning to fly, who have this defect, make bad landings and are apt to crash, because they are unable to judge their distance from the ground when they wish to land. They are quite conscious of the failure and sometimes say that "they do not know where they are when they come near the ground." They are put through a course of training to render their binocular vision more stable and constant; if then they lose the defect, they may become excellent pilots.

Similarly in reference to squint: "Strabismus exists where there is deviation in the direction of the eyes, so that the visual axes are not directed to the same object," is the definition given by Mr. Hartridge. No mention is made of defect of vision; and this definition includes pathological conditions remote from those of ordinary cases of children's squint. Yet no case of children's squint ever existed at one and the same time with binocular vision : all signs of squint disappear when binocular vision is restored, and 
nothing less than the restoration of binocular vision can be regarded as success in the effort to remedy it.

By means of the binoscope (see abstract p. 590) one is able to observe that the eyes apparently deviate because they do not both see at the same time. In this apparatus three ordinary playing cards can be placed in a row so that the patient sees the centre card with both eyes, that on the right with the right eye only, and that on the left with the left eye only. Most children with squint when asked how many cards they can see, reply at once "three"; both eyes see the cards with binocular vision and the deviation ceases to be observable for the time. Some children see four cards at first, the centre one twice, but after some practice they see three readily with no other stimulus than that of vision with both eyes at the same time brought about by the binoscope.

Thus both in squint and in heterophoria one-eyed vision instead of binocular vision is the defect of sight, and deviation is associated with it. For practical purposes a new definition of each of the terms is needed. I suggest the following :

Defect of vision in which binocular vision is absent, and there is deviation in the direction of the eyes, so that the visual axes are not directed to the same object. This definition includes both squint and heterophoria. In heterophoria the conditions described are occasional. In squint they are sufficiently constant to be regarded as permanent. The association of deviation of the visual axes with absence of binocular vision is too constant to be omitted. The inclusion of these two conditions renders the definition a clinical picture of the cases met with, and finds a connotation for each of the terms squint and heterophoria which corresponds with observed facts.

Definite meanings must also be specified for several other terms in order that they may convey the meaning intended when they are used.

By binocular vision is meant central vision with both eyes of the object looked at. Straight lines from the object through the nodal points of each eye fall upon the macula of each eye. This is shown in the drawings which also show the position of the nodal points near the posterior surface of the lens. The object must be taken as the origin of the lines, because it is the only point which is common to both of them. Moreover, the movements of the eyes in binocular vision are pivoted on the object, and without any conscious effort maintain that relation as the object moves, or when the head is moved. Moreover, the axis of binocular vision passes through this point. It does not correspond to the visual axis of either eye, but passes from a point between them through the point in the object where the visual axes of each eye meet. When there is deviation the lines from the object through the nodal points do 
not fall on the macula of each eye. In convergent squint when the line from the object passes through the nodal point and falls on the macula of one eye, the line from the object through the nodal point of the other eye does not fall on the macula, but on the nasal side of it. The cornea is rotated inwards, the macula is rotated outwards and the line from the object through

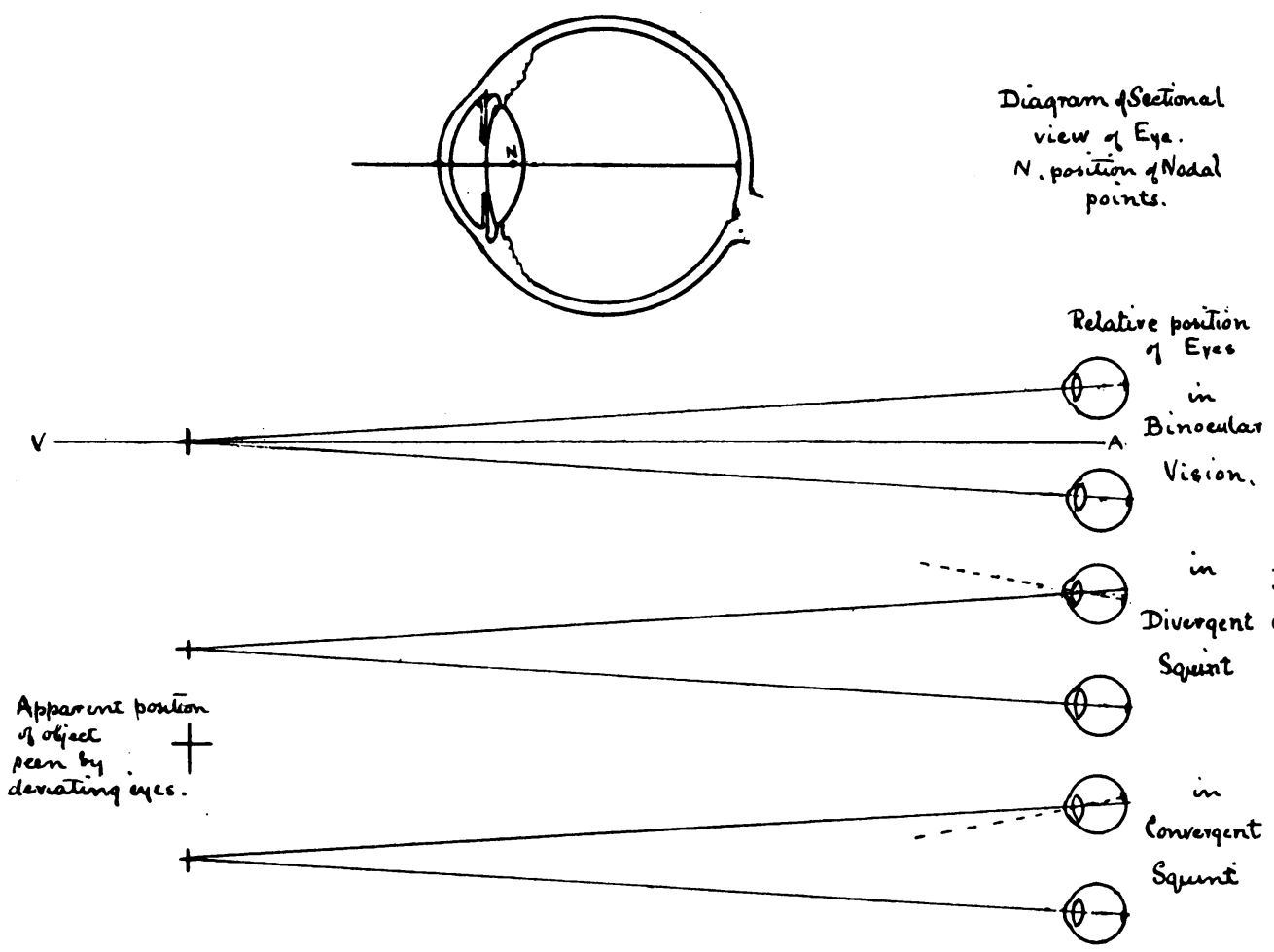

the nodal point falls on the inner or nasal side of the macula, and the object is seen as if it were moved to the same side, or not seen.

In divergent squint the cornea is rotated outwards, the macula is rotated inwards, the line from the object through the nodal point falls on the outer (temporal) side of the macula in the divergent eye, and the object, if seen, is displaced to the opposite side. The diagram serves to show these conditions.

Diplopia is thus the natural proof that binocular vision does not exist. It is evidence of a step towards it in children's squint, for it shows that there is vision in both eyes at the same time, and central vision in both is practically certain to follow as the power to retain vision in both increases. By means of the binoscope this transi- 
tion can be observed; the binocular vision, at first occasional, becomes more frequent before it becomes a constant condition. The central line $\mathrm{V} \mathrm{A}$ in the figure may be taken to represent the visual axis in binocular vision; it marks the direction in which the object is seen.

When the two eyes are not held by looking at one object, their relative position may be called their position of rest, which is thus their relative position when binocular vision is absent. Their correct attitude to one another is assumed to be with their visual axes parallel or nearly so, and any departure from this is termed a deviation.

The nature of the association of the two clinical facts recorded in the definition must next be ascertained if possible. In the investigation the simpler term "one-eyed sight" may safely replace the more cumbersome "absence of binocular vision," for diplopia is conspicuous by its absence in children's squint.

The nature of the association is revealed in Donders' experiment.

This experiment shows how a temporary artificial squint can be brought about in a person with normal sight; that is, with good sight in each eye, no refractive error, and good binocular vision. Such an individual is asked to look at a near object, the point of a pencil for example. One eye is then covered with a card so that the object is seen by one eye only. A concave lens is then placed before the uncovered eye, and a movement of convergence is seen to take place in the eye which is covered; that is, a movement of convergence in the eye which does not see, in association with a change of accommodation in the eye which sees. That is the temporary artificial squint which the experiment set out to obtain. The movement of convergence belongs to binocular vision. It is one of the two movements of fixation with both eyes at the same time, when they are directed from a more distant to a near object; accommodation is the other. This movement would not therefore be expected in persons in whom binocular vision had never existed; it is good evidence that binocular vision has existed. The first step in the actual experiment is covering one eye; bringing about one-eyed sight in a person who has been accustomed to use both eyes in binocular vision. The eye when it is covered moves to its position of rest. This can be observed before proceeding to the next step by removing the card and watching the rapid movement of the eye from the position of rest to that of fixation. The final step in the experiment, placing the concave lens before the uncovered eye, shows that the position of rest of the eye which does not see is moved in the direction of convergence in association with the accommodation of the eye which sees. A temporary 
deviation in the position of rest. When these initial movements are repeated again and again, as the hypermetropic eye is being used for near vision, and a permanent deviation in the position of rest is observed to follow, the conclusion that the repeated initial movements caused the deviation is a reasonable one, and the correspondence of the deviation with the refractive error renders the conclusion a practical certainty. That is the explanation of the deviation in children's squint. One-eyed sight in one in which binocular vision has existed is the necessary association of conditions for its production. The previous binocular vision provides the initial movernents. The one-eyed sight leaves the eye passive in its position of rest to respond to them without control from its own vision. The refractive error determines the direction of the prevailing initial movements. The fact that divergent squint is associated with myopia gives good reason for believing that corresponding initial movements of abduction follow the change of focus from a near to a distant object.

The nature of the association of the two clinical facts recorded in the definition is thus made clear in reference to convergent squint by the addition of one more clinical fact, the period of its appearance, childhood. The arrest of development of binocular vision in hypermetropic children is the cause of convergent concomitant squint in children.

The three facts which concur in the production of temporary artificial squint are: (1) previous binocular vision ; (2) one-eyed sight ; (3) initial movement in the eye which does not see in association with a change of focus (accommodation) in the eye which sees. Add to these the clinical fact of childhood and the term arrest of binocular vision appears to be the correct one to describe the actual production of convergent squint in hypermetropic children.

The converse experiment is easily made; namely, the temporary restoration of binocular vision, and the temporary disappearance of squint. The binoscope test is a temporary restoration of binocular vision and a temporary disappearance of the squint. 'Take away the binoscope, binocular vision ceases and the eye returns to its abnormal position of rest; the squint is seen as before. It is obvious that the essential fact is the presence or the absence of binocular vision.

The clinical facts of occasional or periodic squint show the same sequence of events. The child sees sometimes with binocular vision, and while doing so presents no obvious indication of any unusual condition of his eyes. Nevertheless the squint appears at times; that is, he uses one-eyed sight at times, and then the deviation shows itself, for the eyes then occupy their relative position of rest, and its abnormal position is seen. In these cases and in the experimental cases with the binoscope it cannot be imagined 
that the position of rest alters when binocular vision is used. When both eyes fix the same object, the movements of each eye are pivoted on the object, and their relative position is controlled by their own sight of it. The position of rest remains the same but they are not in it.

In testing a number of children by means of the binoscope recently one case afforded further interesting evidence. Each child was tested both with glasses and without. A boy, aged eight years, saw the three cards as three with his glasses (binocular vision), but saw four cards without them (central vision with one eye only). An opportunity for repeating the test two months later showed the same result. He was using $+5 \mathrm{D}$. glasses. Without them his vision was obviously not sufficiently clear to bring about binocular vision. It is easy to understand that many hypermetropic children make good progress in acquiring binocular vision at games out of doors and in all ordinary use of their sight, and that, when they are required to use their sight for prolonged near vision in looking at books and the like, their vision is not sufficiently clear to bring about binocular vision, and one-eyed sight is used instead. The unused eye becomes less and less sensitive as this is repeated, so that they lose the binocular vision which they had previously acquired for outdoor pursuits, one-eyed sight is completely established, deviation follows and is observed, glasses are worn which check the progress of the deviation, but do not restore the loss of sensibility of the unused eye. It is this restoration to normal sensibility which the binoscope brings about by daily exercising it, and it can only succeed by perseverance until both eyes begin to be used at the same time without the aid of the binoscope, that is, until they are used in ordinary vision, and then ordinary pursuits become natural exercises in establishing and cultivating binocular vision. There is no attempt to interfere with the movements of the eyes except through the natural source of their movements, the sight of the eye itself, when this is sufficiently assured to be maintained at the same time as that of the other eye, the natural irresistible impulse "for single vision" brings about fixation with both eyes at the same time, provided both eyes see the same objects, at first occasionally and then constantly. Whether the position of rest still remains abnormal ceases to be a matter of interest. In heterophoria there is obviously the same sequence of events. In both there is arrest of development of binocular vision. The difference is that in heterophoria the patient has been able to retain such binocular vision as he has already acquired when further progress is arrested, whereas the patient with squint lost that in consequence of its arrest.

The successful treatment of heterophoria is training the power to retain vision with both eyes at the same time. The ineffectual 
effort to retain vision in both is observed in the asthenopia which follows heterophoria.

The binometer is useful for this purpose. The principle of its construction is well known. The binometer serves to train the power to retain vision with both eyes at the same time, as well as to measure the power to retain it.

Deviation is thus the objective sign of absence of binocular vision ; evidence that it has been absent long enough in near vision to disturb permanently the relative position of rest of the two eyes, in convergent squint. In children it is evidence that the development of binocular vision has been arrested. This is the failure in development of a natural faculty which depends upon retaining sight in both eyes at the same time; and the binoscope demonstrates how easily the power to retain sight in both eyes at the same time can be restored and cultivated in children. The education of a natural faculty until the first step in it is fully acquired.

An unusual patient came under my care a good many years ago. A boy aged four years who could not walk. Nothing was discoverable in bones, muscles or joints to account for it ; he shuffled about the room in a half-sitting position quite actively. His mother was directed to put him on his feet and to try to make him bear his weight on them, and to keep on trying till he did so. He very soon acquired the use of his legs and ran about like other children. He seems to have been allowed to retain his baby way of getting about, until custom made him content with it. Something like this is happening with the natural use of both eyes in binocular vision, and as the movements of walking followed naturally from the sensation of supporting the weight on the feet, so the natural movements of binocular vision follow sight with both eyes at the same time. Bring about sight of the same object with both eyes at the same time, and Nature does the rest. There is no other road to success.

\section{Note on the Stereoscope and the Binoscope}

"The goal at which all treatment should aim is the establishment of binocular vision." With this sentence Mr. Juler opens the subject of the treatment of strabismus. The systematic use of some form of stereoscope is prescribed to attain this goal.

In the use of the stereoscope two objects (pictures) are employed, and each eye sees only the picture which it is intended to see. The field of vision of each eye is thus completely screened from that of the other, and no real object is seen by both eyes, which can be fixed by both in binocular vision. To supply such an object the two pictures are made to appear to occupy the same place and to 
appear as one, and it is this fictitious object, formed by the fusion of the two pictures by the apparatus itself, which the two eyes are able to fix in binocular vision.

When a person with normal sight looks through a stereoscope he is able to adjust it by means of his binocular vision so that the object appears as one.

In squint there is absence of binocular vision. It is doubtful whether adjustment is ever accurate, and the stereoscope fails as a means of treatment.

The binoscope, by presenting to both eyes in the central part of the field of vision, which is unscreened, the same actual objects, instead of the fictitious substitute employed in the stereoscope, induces binocular vision without difficulty and succeeds as a means of treatment. In using the binoscope the screened lateral parts of the field of vision bring about simultaneous vision with both eyes; and binocular vision of objects in the central unscreened part of it readily follows in most cases of squint, so that the squint at once disappears for the time, and its permanent disappearance is effected by systematic daily use. In a few cases, perhaps one in ten, there is diplopia at first, which the use of the binoscope distinguishes from binocular vision. A number of school children with squint, who were being treated by means of the amblyoscope, were thus tested by means of the binoscope. They showed a much larger percentage of diplopia. It was present in about half the cases tested. In squint, training with a separate picture for each eye thus appears to induce diplopia, not binocular vision.

\title{
FUNCTIONAL DIPLOPIA IN A SCHOOLBOY
}

\author{
BY
}

\section{Allister M. MacGillitiray}

SURGEON TO THE DUNDEE EYE INSTITUTION, ETC.

THE following is an interesting and unusual case of duplication of letters, words and figures in a schoolboy, without any discoverable organic cause. As far as can be ascertained, no similar case has been reported, and no mention of the condition can be found in the text books of ophthalmology.

John D, aged 8 years, a healthy, highly intelligent boy, was brought by his mother for consultation on account of periodic attacks of double vision of some six months' duration. Latterly the attacks had recurred with greater frequency, the double vision 